Article

\title{
Identifying Seasonal Groundwater Recharge Using Environmental Stable Isotopes
}

\author{
Hsin-Fu Yeh, Hung-I Lin, Cheng-Haw Lee *, Kuo-Chin Hsu and Chi-Shin Wu \\ Department of Resources Engineering, National Cheng Kung University, Tainan 701, Taiwan; \\ E-Mails: hfyeh22@gmail.com (H.-F.Y.); mariolin226@gmail.com (H.-I.L.); \\ kchsu@mail.ncku.edu.tw (K.-C.H.); axin1026@gmail.com (C.-S.W.) \\ * Author to whom correspondence should be addressed; E-Mail: leech@mail.ncku.edu.tw; \\ Tel.: +886-6-275-7575 (ext. 62833); Fax: +886-6-238-0421.
}

External Editors: Trevor Elliot and Luc Lambs

Received: 24 March 2014; in revised form: 12 September 2014 / Accepted: 19 September 2014 / Published: 26 September 2014

\begin{abstract}
In this study, the stable isotope values of oxygen and hydrogen were used to identify the seasonal contribution ratios of precipitation to groundwater recharge in the Hualien River basin of eastern Taiwan. The differences and correlations of isotopes in various water bodies were examined to evaluate the groundwater recharge sources for the Hualian River basin and the interrelations between groundwater and surface water. Proportions of recharge sources were calculated based on the results of the mass balance analysis of the isotope composition of hydrogen and oxygen in the basin. Mountain river water accounted for $83 \%$ and plain rainfall accounted for $17 \%$ of the groundwater recharge in the Huanlian River basin. Using the mean $d$-values, a comparison of $d$-values of precipitation and groundwater indicates the groundwater consists of $75.5 \%$ wet seasonal sources and $24.5 \%$ dry seasonal sources, representing a distinct seasonal variation of groundwater recharge in the study area. Comparisons between hydrogen and oxygen isotopes in rainwater showed that differences in the amount of rainfall resulted in depleted oxygen and hydrogen isotopes for precipitation in wet seasons as compared to dry seasons. The river water contained more depleted hydrogen and oxygen isotopes than was the case for precipitation, implying that the river water mainly came from the upstream catchment. In addition, the hydrogen and oxygen isotopes in the groundwater slightly deviated from the hydrogen and oxygen isotopic meteoric water line in Huanlian. Therefore, the
\end{abstract}


groundwater in this basin might be a mixture of river water and precipitation, resulting in the effect of the river water recharge being greater than that of rainfall infiltration.

Keywords: stable isotopes; groundwater recharge; Hualien River basin

\section{Introduction}

Oxygen and hydrogen isotopes of water are widely used as tracers to understand hydrogeological processes such as precipitation, groundwater recharge, groundwater-surface water interactions, and basin hydrology [1-6]. A comparison of the oxygen and hydrogen isotopic compositions of precipitation and groundwater provides an excellent tool for evaluating the recharge mechanism [7-11]. Determining the sources of groundwater recharge is important for the effective management of groundwater resources.

In hydrology, fractionation of $\delta^{18} \mathrm{O}$ and $\delta \mathrm{D}$ is driven by kinetic processes during evaporation and condensation [12]. In the process of oceanic water evaporation becoming inland rainfall, a sequence of isotope fractionations causes variations in the composition of the isotope values of oxygen and hydrogen in continental meteoric water. Since this fractionation process is based on the equilibrium processes of the isotopes of evaporation and condensation, there is a specific relationship that governs the distributions of isotope values of oxygen and hydrogen in rainfall.

The empirical equation was found by Craig [13] when he used a linear regression method to analyze the composition of the isotopes of oxygen and hydrogen in samples of precipitation, snow water, and river water from all over the world. His finding is known as the Global Meteoric Water Line (GMWL):

$$
\delta \mathrm{D}=8 \delta^{18} \mathrm{O}+10
$$

A later study by the IAEA (International Atomic Energy Agency), water samples from rainfall stations were collected globally showing a similar result $[12,14]$ :

$$
\delta \mathrm{D}=(8.17 \pm 0.08) \delta^{18} \mathrm{O}+(10.56 \pm 0.64)
$$

Most of the precipitation in the world follows this relationship. However, some specific areas that have different evaporation and condensation conditions (e.g., temperature and humidity), or that have a unique terrain environment, create their own special local meteoric water line with a different slope and intercept $[12,15]$. In the meteoric water line of oxygen and hydrogen isotopes, the slope represents the ratio of the temperature relationship between $\delta \mathrm{D}$ and $\delta^{18} \mathrm{O}$ when condensation occurs; the value of the intercept is based on the evaporative conditions in the water source region.

The intercept is also called deuterium excess or $d$-excess $\left(d=\delta \mathrm{D}-8 \delta^{18} \mathrm{O}\right)$ [14]. The intercepts in most places around the world are about 10\%. However, areas may have different slopes and intercepts due to different rainfall evaporation conditions or source evaporation conditions in various air mass sources. For example, North America: $\delta \mathrm{D}=7.95 \delta^{18} \mathrm{O}+6.03$ [12]; Tropical Island area: $\delta \mathrm{D}=6.17 \delta^{18} \mathrm{O}+3.97$ [12]; Japan: $\delta \mathrm{D}=8 \delta^{18} \mathrm{O}+17.5$ [16]. Generally speaking, if evaporation is faster, or if rainfall evaporation occurs, intercepts are higher. Some studies have used $d$-excess to identify the air mass source of meteoric water and to define the seasonal recharge of groundwater $[4,5,7,17]$. 
Taiwan is located in the West Pacific Ocean monsoon climate area. The air mass of the Northeast monsoon prevalent in winter originates from the Antarctic Continent. The air mass of the Southwest monsoon prevalent in summer originates from the equator in the Pacific Ocean and from the North Pacific Ocean tropical marine air mass. Rainfall in Taiwan is related to these three air masses. The summer rainfall in Taiwan is mostly typhoon cloudbursts and afternoon rainfall caused by thermal convection. Due to the effects of the Central Mountain Range, Northern Taiwan faces the Northeast monsoon [18]. During the winter, southward cold fronts bring plentiful water vapor from the East China Sea which results in rainfall. Although Eastern Taiwan is to the east of the Central Mountain Range, rainfall is low because the Northeast monsoon moves parallel to the coast. In addition, Western Taiwan, protected by the Central Mountain Range, is not obviously affected by the Northeast monsoon, causing winter drought [18].

The purpose of this study is to use oxygen and hydrogen isotopes as natural tracers to identify the possible sources of groundwater and the seasonal variations in groundwater recharge in the eastern Taiwan Huanlian River basin. The results provide useful information about hydrological processes, such as the interaction of precipitation, river water, and groundwater.

\section{Study Area}

The Huanlian River is located in the Huatung Valley in Hualian County, Eastern Taiwan. To the north, this river connects with the Taroko River system basin; to the west, it is adjacent to the Chuoshui River; to the south, it is next to the Xiuguluan River basin; and to the east, it is next to the Fengping River system basin (Figure 1). The Hualian River originates from Bazi Mountain, which is a sub-range of the Dan Mountain. The main stream is approximately $57.28 \mathrm{~km}$ long, with a basin area of $1507 \mathrm{~km}^{2}$ and an annual runoff of 3813 million $\mathrm{m}^{3}$. The Hualian River basin water resources are primarily used for agriculture irrigation, followed by domestic and industrial water use. Despite the rich amount of surface water offered by the Huanlian River, the surface runoff during wet and dry seasons fluctuates significantly. Each year's high-flow period starts from May to October, which accounts for $70 \%$ of the runoff of the entire year. After October, the flow declines significantly, and the driest period occurs in February and March. From November to April of the following year, the runoff in the drought period accounts for approximately $30 \%$ of the annual runoff.

The main stream of the Huanlian River exits the valley from Dafong Mountain and enters the plains areas. It flows along Huatung Valley from southwest to northeast. The primary sub-ranges include the Guangfu River, the Maan River, the Wanli River, the Shoufeng River, and the Mugua River. These rivers run into the ocean near Hualian Mountain, at the north of the Coastal Range. The hydrogeology of the Hualian River basin can be divided into three areas based on location: the Central Mountain Range, Huatung Valley, and the Coastal Range. Depending on the terrain, Hualian can be divided into two sections, Hualian Plain and Huatung Valley Plain. Hualian Plain is located to the north of Huatung Valley. Good gravel aquifers can be found at depths of 80-90 m underground. The width of the Huatung Valley's shallow gravel layer tends to become thinner from the top to the bottom of the alluvial fan, whereas the deeper layer is characterized by coarse sands and occasional mud layers. With respect to geological characteristics, Huatung Valley is located at the line of collision between the Eurasian Plate and the Philippine Sea Plate. The two sides of the valley are delimited by upthrust with high angles. 
Hualian River is abundant in runoff and high in sediment transport capacity. Most surface water is utilized for agricultural purposes, whereas domestic and industrial water rely on the copious amount of available groundwater. To understand the use of water resources in this basin, the fundamental characteristics and recharge sources of the groundwater need to be analyzed. Based on the effective fractional porosity volume in the alluvium, it can be determined that the groundwater reserve in the Hualian River basin is approximately 5 billion $\mathrm{m}^{3}, 370$ million $\mathrm{m}^{3}$ of which can be exploited per year [19]. Based on water balance, the river infiltration recharge for the whole region is 1.45 billion $\mathrm{m}^{3}$ [20]. A report published by the Taiwan Water Resource Agency [21] shows a simulation of the hydraulic characteristics of regional groundwater using the MODFLOW model in the Groundwater Modeling System (GMS). According to the results of the groundwater budget in the Hualian River basin, $27 \%$ of the infiltration is direct rainfall, $18 \%$ of the recharge is the lateral flow of boundary, and $55 \%$ of the groundwater recharge comes from river water.

Figure 1. The location of the study region. Precipitation sampling sites (circles), river water (squares), and groundwater (triangles) samples are shown.

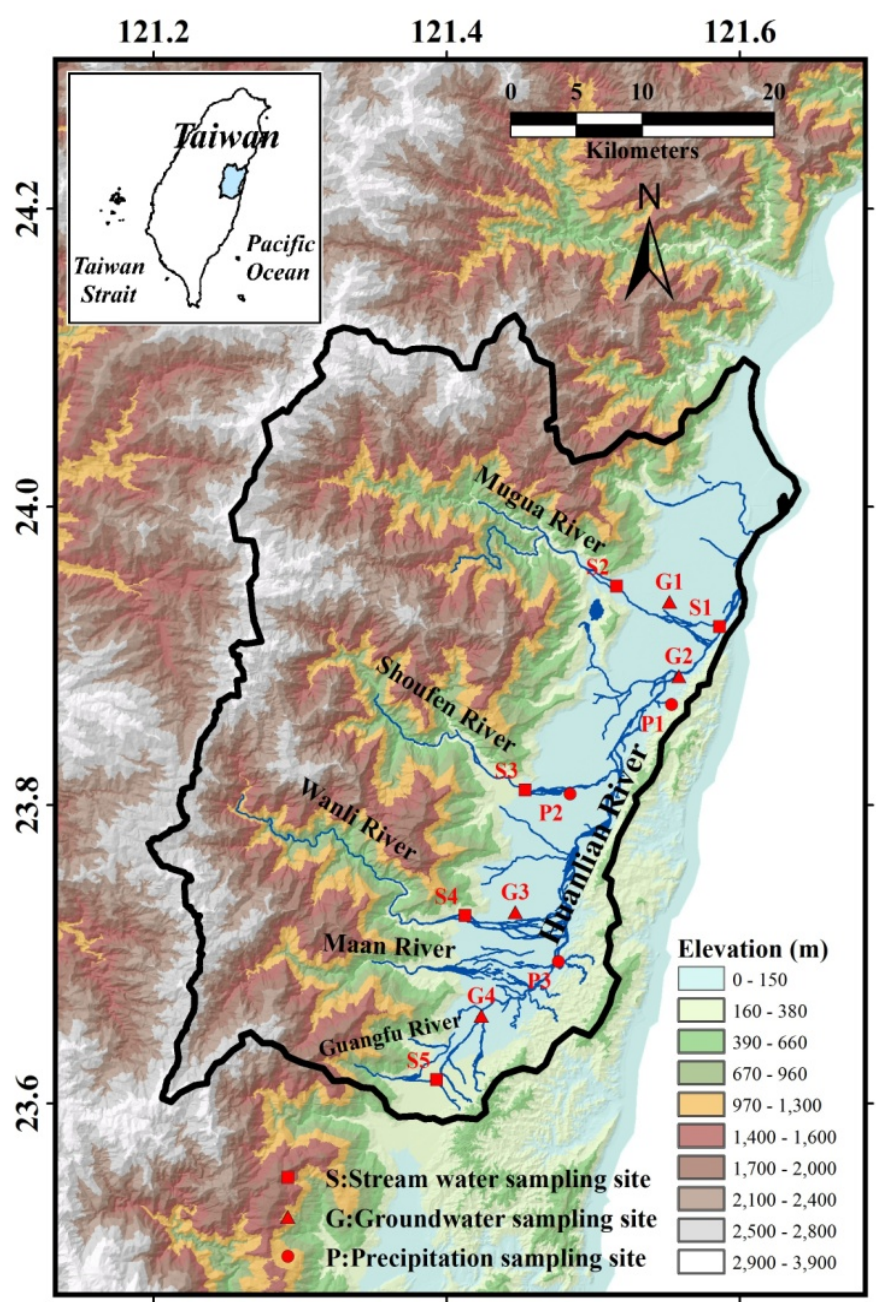

\section{Sampling and Analytical Method}

Precipitation, river water, and groundwater samples were collected for oxygen and hydrogen isotopic analyses from 2003 to 2012. Sampling was carried out during both wet and dry periods. Sampling 
procedures for precipitation were in accordance with IAEA guidelines [22]; in short, the procedures are designed to avoid evaporation of precipitation samples. Sampling locations are shown in Table 1 and Figure 1. Stable oxygen isotopic compositions were analyzed using the $\mathrm{CO}_{2}-\mathrm{H}_{2} \mathrm{O}$ equilibration method [23]. The equilibrated $\mathrm{CO}_{2}$ gas was measured using a VG SIRA 10 isotope ratio mass spectrometer. The hydrogen isotopic compositions were determined on a VG MM602D isotope ratio mass spectrometer after water was reduced to $\mathrm{H}_{2}$ using zinc shots made by the Biogeochemical Laboratory of Indiana University [24]. All isotopic ratio results were reported as the $\delta$-notation (\%o) relative to the international VSMOW (Vienna Standard Mean Ocean Water) standard. The precisions $(2 \sigma)$ for $\delta^{18} \mathrm{O}$ and $\delta \mathrm{D}$ were $0.1 \%$ and $1.5 \%$, respectively.

Table 1. Sampling locations of the study region.

\begin{tabular}{cccc}
\hline Site & Longitude & Latitude & Elevation $(\mathbf{m})$ \\
\hline S1 & 121.59 & 23.92 & 7 \\
S2 & 121.52 & 23.95 & 96 \\
S3 & 121.45 & 23.81 & 140 \\
S4 & 121.41 & 23.73 & 143 \\
S5 & 121.39 & 23.62 & 160 \\
P1 & 121.55 & 23.87 & 76 \\
P2 & 121.48 & 23.81 & 91 \\
P3 & 121.48 & 23.70 & 106 \\
G1 & 121.55 & 23.94 & 52 \\
G2 & 121.56 & 23.89 & 18 \\
G3 & 121.45 & 23.73 & 110 \\
G4 & 121.42 & 23.66 & 116 \\
\hline
\end{tabular}

\section{Results and Discussion}

\subsection{Isotopic Compositions of Precipitation}

For the purposes of this study, a total of 385 samples of precipitation in the Hualian River basin were analyzed to discuss the characteristic isotopic signatures of precipitation. The $\delta \mathrm{D}$ of the precipitation was between $-149.5 \%$ and $22.7 \%$, with a mean of $-22.9 \%$ $\pm 31.9 \%$. The $\delta^{18} \mathrm{O}$ ranged between $-20.2 \%_{0}$ and $1.5 \%$, with a mean $-4.4 \%$ o $\pm 3.7 \%$. The mean $d$ was $12.1 \%$. Linear regression analysis showed the Local Meteoric Water Line (LMWL) of the Hualian River basin to be $\delta \mathrm{D}=8.40 \delta^{18} \mathrm{O}+13.89$.

In this study, two local meteoric water regression lines (LMWL) were plotted to describe the isotopic data for different seasons: $\delta \mathrm{D}=8.03 \delta^{18} \mathrm{O}+9.73$ for the wet season precipitation (May to October) and $\delta \mathrm{D}=8.04 \delta^{18} \mathrm{O}+15.03$ for the dry season precipitation (November-April). The slope and intercept of the regression line for the wet season precipitation are virtually identical to those of the global meteoric water line (GMWL) of Craig (1961) [15]. The dry season precipitation was found to have an intercept of 15.03, which is much higher than that of the GMWL of 10 due to the different air masses affecting the study (see Figure 2).

In this study, the isotopic composition of precipitation during the wet and dry seasons in Hualian was also examined. The $\delta \mathrm{D}$ in wet seasons ranged between $-149.5 \%$ and $17.5 \%$, with a mean of $-40.6 \%$ o $\pm 32.8 \%$. The $\delta^{18} \mathrm{O}$ was between $-20.2 \%$ and $0.8 \%$, with a mean of $-6.3 \%$ o $\pm 4.1 \%$. The mean of $d$ was $9.5 \%$. The $\delta \mathrm{D}$ in dry seasons ranged between $-69.8 \%$ and $22.7 \%$, with a mean of 
$-3.7 \%$ o $\pm 16.1 \%$. The $\delta^{18} \mathrm{O}$ was between $-9.6 \%$ and $1.5 \%$, with a mean of $-2.3 \%$ $\pm 1.9 \%$. The mean of $d$ was $14.7 \%$. More depleted composition of hydrogen and oxygen isotopes was found in the summer wet seasons than the dry seasons. This feature has been commonly observed in other regions of Taiwan [18,25-27]. In Taiwan, the composition of hydrogen isotopes, compared to the rainfall of the Northeast monsoon in winters, is depleted in the rainfall of the Southwest monsoon in summers. As for the effects of temperature, higher temperature may have enriched the signatures of hydrogen and oxygen isotopes in precipitation. In seasons with great rainfall, the rainfall amount effect [12] caused by the rain out of heavy precipitation amounts over a relatively short time duration, the hydrogen and oxygen isotopes in precipitation are significantly depleted. Thus, rainfall also has an effect on isotopes. Temperature and rainfall amount exert opposite effects on the fractionation of hydrogen and oxygen isotopes. Moreover, the isotopes in the Hualian River basin are depleted more in wet seasons than is the case in dry seasons. The signatures of hydrogen and oxygen isotopes can be explained by the mutual influence of rainfall amount and temperature, with the former have a stronger effect than the latter. During rainy seasons in the summer, rainfall is often heavier with a greater amount of rainfall during a specific period of time and so a higher precipitation rate, despite higher temperatures. Consequently, the composition of the hydrogen and oxygen isotopes at this time is depleted relative to $\delta^{18} \mathrm{O}$ and $\delta \mathrm{D}$. Yurtsever and Gat (1981) [28] have pointed out generally that the temperature effect is normally pronounced in high-latitude continental regions, whereas the amount effect is pronounced in tropical regions. It is well known that the hydrogen and oxygen heavy isotope contents of precipitation decrease with increasing altitude. In this study, precipitation sites are located in the lowest area of the basin. Therefore, in this study it is difficult to discuss the range of altitude effect in the basin. Precipitation sites may not adequately represent the average precipitation in the basin. If the altitude effect is large, groundwater can also derive from precipitation in the mountainous area with depleted isotopic compositions similar to streams.

Figure 2. Plot of $\delta \mathrm{D} v s . \delta^{18} \mathrm{O}$ for precipitation samples. LMWL represents the local meteoric water line.

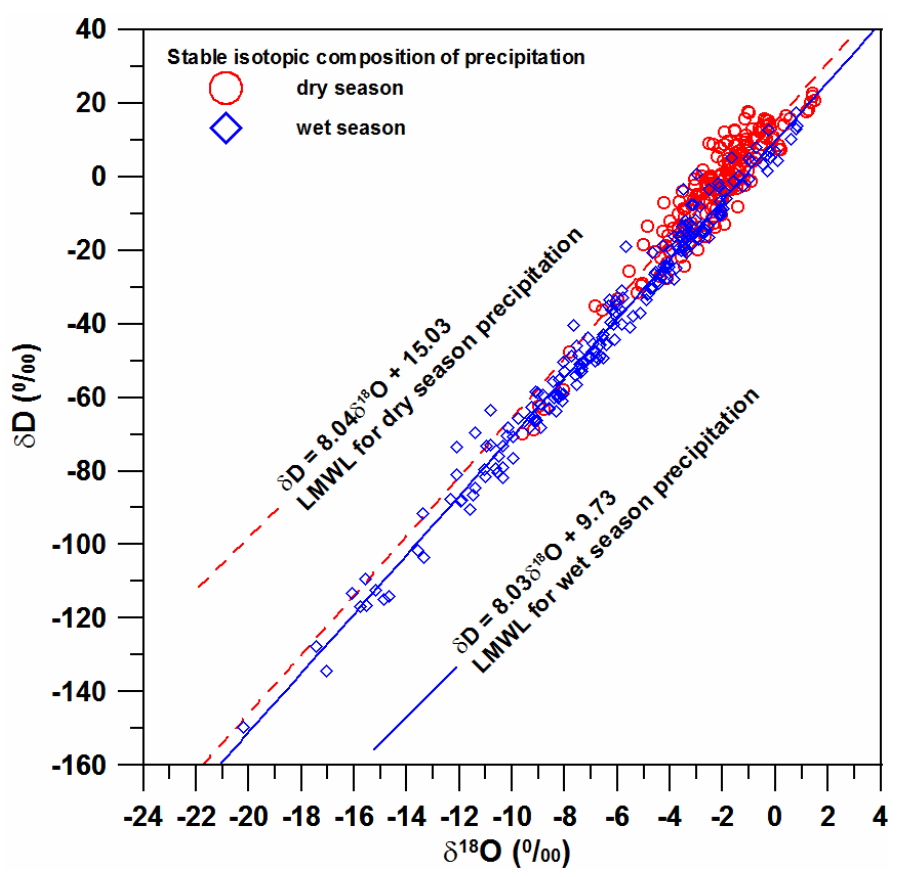




\subsection{Isotopic Compositions of River Water}

The $\delta \mathrm{D}$ of the river water in the Hualian River basin was between $-70.0 \%$ and $-46.2 \%$, with a mean of $-61.3 \%$ $\pm 5.9 \%$. The $\delta^{18} \mathrm{O}$ ranged between $-10.3 \%$ and $-7.8 \%$, with a mean of $-9.1 \%$ $\pm 0.6 \%$ o (Figure 3). The comparison of hydrogen and oxygen isotope compositions between rainwater and river water demonstrated that the composition of the hydrogen and oxygen isotopes from river water matched that of the local meteoric water across the Hualian River basin. This indicated that rainfall is the primary source of the river water. Furthermore, the composition of the hydrogen and oxygen isotopes from the river water was more depleted as compared to that of the precipitation in the valley, indicating that the river water is composed of rainfall in the upstream catchment. Therefore, the precipitation in the valley had smaller effects on the river water. In wet seasons, the hydrogen and oxygen isotopes exhibited a depleted composition compared to that of dry seasons, a similar phenomenon to the rainwater. Thus, the composition of the rainwater was influenced by the season. In short, it can be concluded that the water recharge of the Hualian River basin is significantly affected by seasonal rainfall. Also, as mentioned, the hydrogen and oxygen isotope composition of the rainfall brought by the Southwest monsoon in the summer is more depleted than that brought by the Northeast monsoon in the winter.

Figure 3. Plot of $\delta \mathrm{D} v s . \delta^{18} \mathrm{O}$ for river water samples. The LMWL is established as $\delta \mathrm{D}=8.40 \delta^{18} \mathrm{O}+13.89$ for local precipitation.

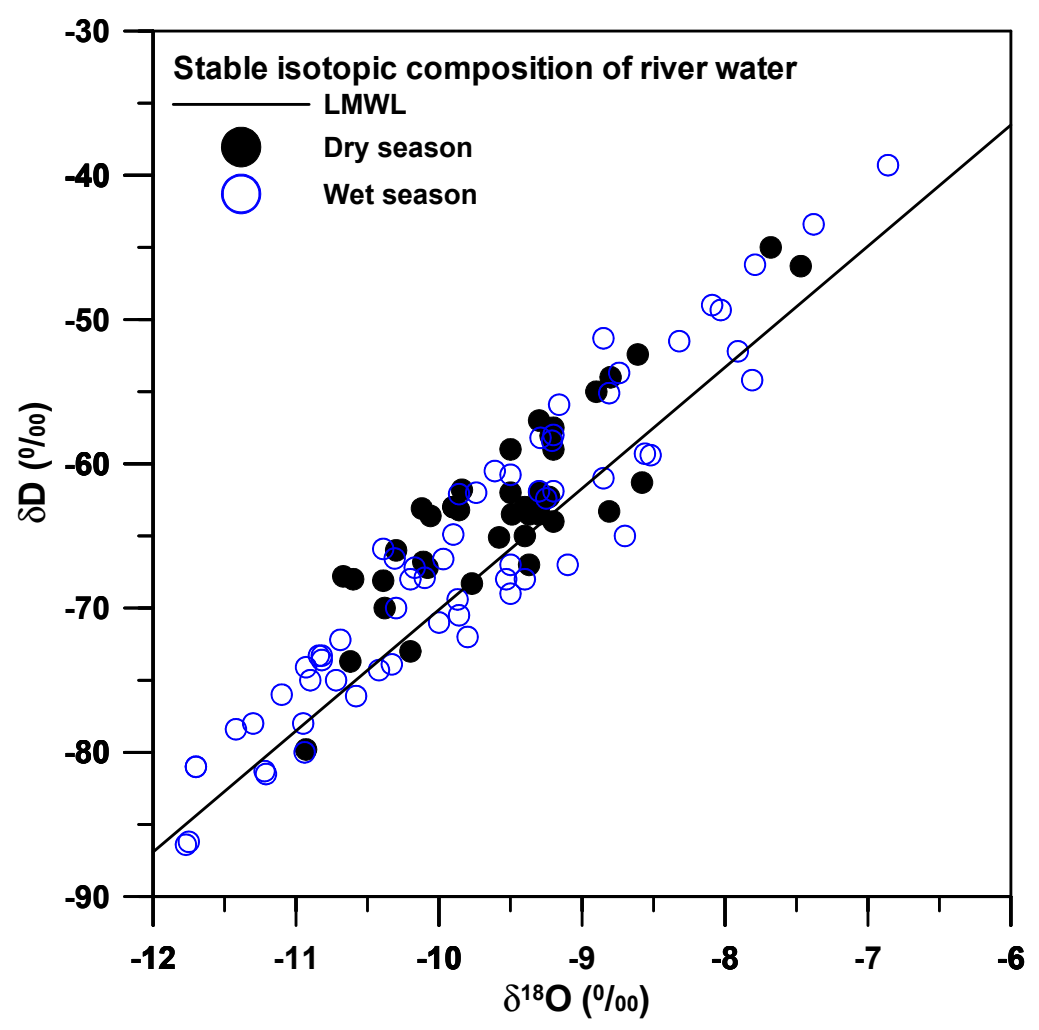

In this study, the signatures of hydrogen and oxygen isotopes for river water in the main stream and tributaries of the Hualian River (the Mugua River, the Shoufeng River, the Maan River, and the Wanli River) were also compared during dry and wet seasons. The results are illustrated in Figure 4. As shown in the figure, significant differences were observed in the hydrogen and oxygen isotope signatures in the mainstream and tributaries of the Hualian River. In wet seasons, streams leak water into the groundwater 
system. Alternatively, water can be discharge from the groundwater to surface waters in dry seasons. Thus, the groundwater compositions were similar to those of the river water, indicating that the source of the groundwater in this area may be related to river water. In both dry and wet seasons, the isotope signatures in the tributaries of the Hualian River were more depleted than those in the mainstream because the tributaries in mountainous catchment areas consisted of primarily interflow before they entered the mainstream. Interflow is the lateral movement of water in the vadose zone, that first returns to the surface or enters a stream prior to becoming groundwater. The interflow blended with groundwater and then joined the Hualian River. Consequently, the compositions in the two were significantly different. These results may need to be verified by collecting related data.

Figure 4. Relationship between $\delta \mathrm{D}$ and $\delta^{18} \mathrm{O}$ for river water in comparison to the main stream and tributaries of the Hualian River during dry and wet seasons. (A) Dry seasons;

(B) Wet seasons.

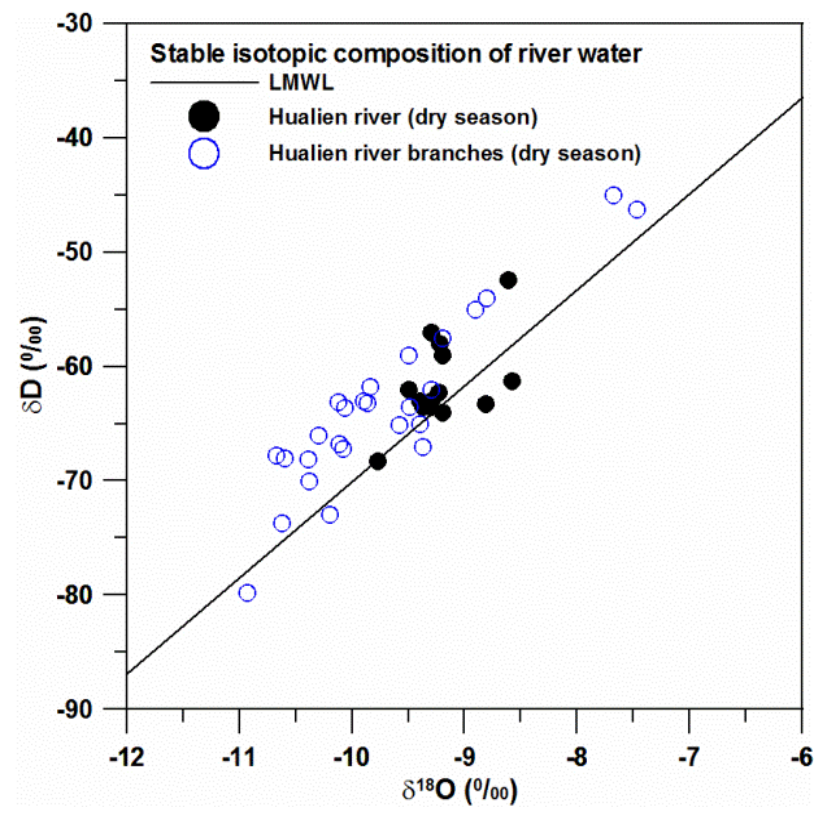

(A)

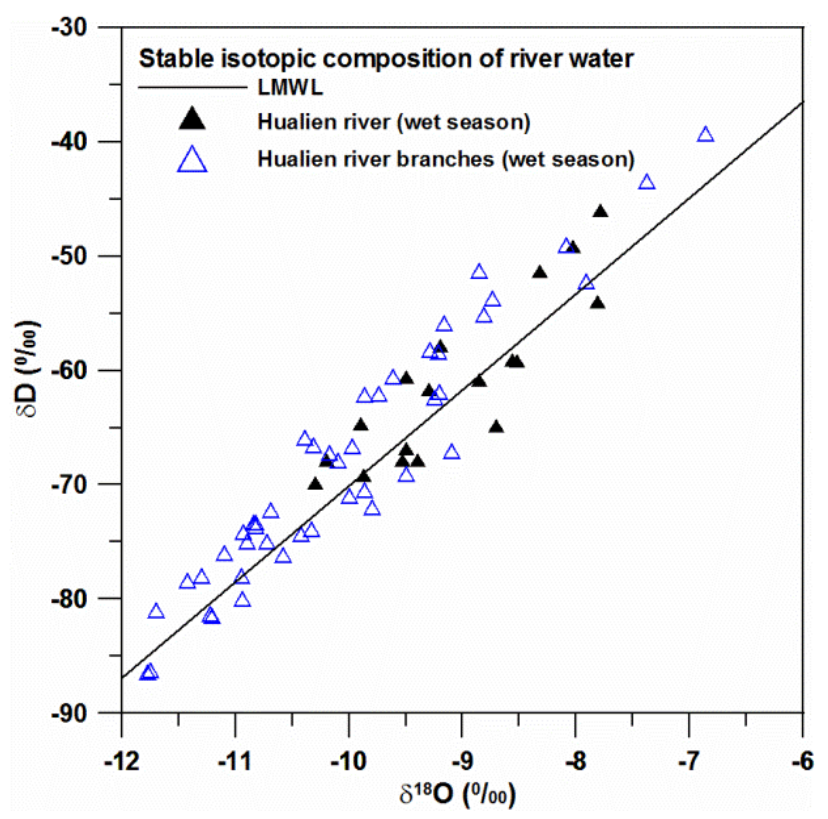

(B)

\subsection{Isotopic Compositions of Groundwater}

This research consisted of an analysis of the groundwater in the Hualian River basin. As illustrated in Figure 5, the hydrogen and oxygen isotope compositions in the groundwater samples obtained from observation wells corresponded to those of the rainfall along the Hualian River basin. The $\delta \mathrm{D}$ of the groundwater in the Hualian River basin was between $-73.7 \%$ and $-42.0 \%$, with a mean of $-56.2 \%$ o $\pm 9.1 \%$. The $\delta^{18} \mathrm{O}$ ranged between $-10.4 \%$ and $-7.2 \%$, with a mean of $-8.8 \%$ $\pm 1.0 \%$ o (Figure 5). The isotopic composition of river water is controlled by the mixing rates of three major components: surface runoff, interflow, and groundwater (base flow). The difference between arrival times for interflow and surface runoff is of the order of hours, so they are both from recent storms and have similar isotopic compositions. Therefore, from the point of view of isotopic composition, river water can be considered as being composed of groundwater and runoff [29]. The basin groundwater is recharged from rainfall and river water. In this study, the groundwater compositions were similar to 
those of the river water, indicating that the source of the groundwater in this area may be related to river water. The primary groundwater source may be river water rather than simply rainfall recharge. In addition, the hydrogen and oxygen isotopes in the groundwater near the Hualian River slightly deviated from the hydrogen and oxygen isotopic local meteoric water line in Hualian. Therefore, the groundwater might be a mixture of river water and rainwater, which explains why the effect of the river water recharge was greater than the rainfall infiltration.

Figure 5. Plot of $\delta \mathrm{D} v s . \delta^{18} \mathrm{O}$ of groundwater samples.

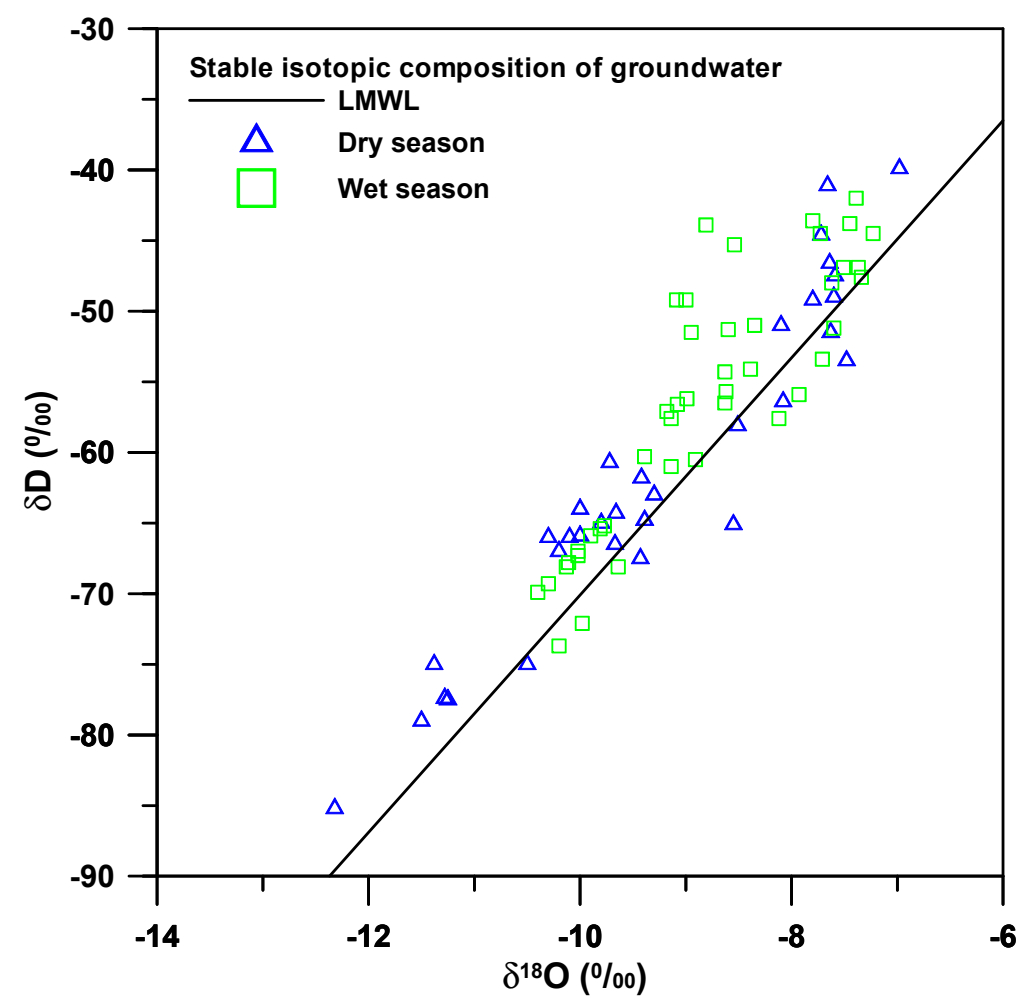

\subsection{Mass Balance Analysis}

The basin groundwater is recharged from rain that falls on the basin and from the tributaries of the Hualian River (the Mugua River, the Shoufeng River, the Maan River, and the Wanli River) drained from mountain watersheds (Figure 1). According to the depth of the well screens $(80-90 \mathrm{~m}$ below ground) and hydro-geological profiles, groundwater from the four wells (G1, G2, G3, and G4) can be classified as shallow groundwater. The meteoric $\delta^{18} \mathrm{O}-\delta \mathrm{D}$ signature is important for understanding the groundwater recharge. The isotopic composition of groundwater equals the average weighted values of recharge sources, such as the annual composition of precipitation and river water. Therefore, deviations of the groundwater isotopic ratio from that of precipitation are expected. The transfer function from precipitation to groundwater must be understood for groundwater provenance studies. The transfer function also provides basic information about the mechanisms of recharge [2]. In this study, the mean value of oxygen isotopic compositions of groundwater for the Huanlian River basin was $-9.65 \%$ (ranging from $-9.32 \%$ to $-10.65 \%$ ). The mean values of oxygen isotopic compositions of dry and wet seasons for the Huanlian River basin were $-4.18 \%$ and $-6.46 \%$, respectively. The ratio of precipitation for dry and wet seasons was 0.19:0.81 from 2000 to 2012 (according to the Central Weather Bureau). 
The weighted average $\delta^{18} \mathrm{O}$ of precipitation was $-6.02 \%$ in the Huanlian River basin. The values of oxygen isotopic compositions of river water for the dry and wet seasons were $-10.20 \%$ and $-10.42 \%$, respectively. The ratio of stream flow for the dry and wet seasons was 0.14:0.86 from 1980 to 2011 (according to the Water Resources Agency). The river water weighted average value for $\delta^{18} \mathrm{O}$ was $-10.39 \%$ in the Huanlian River (see Table 2).

Table 2. Precipitation and river water weighted average $\delta \mathrm{D}, \delta^{18} \mathrm{O}$ and $d$-excess and their standard error.

\begin{tabular}{ccccc}
\hline \multirow{2}{*}{ Weighted Average: } & \multicolumn{2}{c}{ Precipitation } & \multicolumn{2}{c}{ River Water } \\
\cline { 2 - 5 } & Dry Season & Wet Season & Dry Season & Wet Season \\
\hline Ratio & 0.19 & 0.81 & 0.14 & 0.86 \\
n (used for average) & 185 & 200 & 41 & 64 \\
$\delta \mathrm{D}(\%)$ & $-3.7 \pm 16.1$ & $-40.6 \pm 32.8$ & $-62.9 \pm 6.5$ & $-66.2 \pm 10.6$ \\
$\delta^{18} \mathrm{O}(\%)$ & $-2.3 \pm 1.9$ & $-6.3 \pm 4.1$ & $-9.6 \pm 0.7$ & $-9.8 \pm 1.2$ \\
$d$-excess (\%) & $14.7 \pm 5.6$ & $-9.5 \pm 4.6$ & $13.5 \pm 3.2$ & $12.1 \pm 3.5$ \\
\hline
\end{tabular}

In basin water budget studies, it is important to assess the proportion of the precipitation and river water from the mountain that actually recharges the groundwater. The stable isotopic composition of groundwater is determined by oxygen and hydrogen isotopic compositions and recharge percentages of concerned sources. Using mass balance analysis for the oxygen and hydrogen isotopic compositions, the groundwater recharge percentages of every recharge source can be evaluated. In this study, mixing between two distinct recharge sources can be quantified by a simple linear algebraic equation:

$$
\begin{aligned}
& C\left(V_{A}+V_{B}\right)=A V_{A}+B V_{B} \\
& C=A \frac{V_{A}}{V_{A}+V_{B}}+B \frac{V_{B}}{V_{A}+V_{B}}=A(1-X)+B X
\end{aligned}
$$

where $\mathrm{A}$ is the precipitation stable isotope value of the basin; $\mathrm{B}$ is the river water stable isotope value of the mountain watershed; $\mathrm{C}$ is the groundwater stable isotope value of the basin; $\mathrm{V}_{\mathrm{A}}$ is the amount of precipitation; $\mathrm{V}_{\mathrm{B}}$ is the amount of river water; $\mathrm{X}$ is the recharge proportion of river water; and $(1-\mathrm{X})$ is the recharge proportion of precipitation.

Based on stable isotopic characteristics, the results show that $83 \%$ of the groundwater in the Huanlian River basin is derived from river water from the mountain watershed, and $17 \%$ is from the rain that falls on the basin. This indicates that the basin groundwater is mainly recharged from the river water from the mountain watershed, primarily due to the abundant precipitation in the mountain area. Using the mean $d$-value, the relative contributions of the wet and dry seasonal sources to the groundwater recharge can be calculated using a mass-balance equation:

$$
d_{\text {groundwater }}=X d_{\text {wet season }}+(1-X) d_{\text {dry season }}
$$

where $X$ and $(1-X)$ are the fractions of wet and dry seasonal sources, respectively. Based on their $d$-values, the groundwater sources are composed of an average of approximately $75.8 \%$ wet seasonal sources and $24.2 \%$ dry seasonal sources. 


\section{Conclusions}

The present study examined the stable isotopic composition of precipitation, river water, and groundwater in the Hualian River basin. Mountain river water accounted for $83 \%$, and plain rainfall accounted for $17 \%$ of the groundwater recharge in the Huanlian River basin. Comparisons between hydrogen and oxygen isotopes in precipitation showed that differences in the amount of rainfall resulted in depleted oxygen and hydrogen isotopes for precipitation in wet seasons as compared to dry seasons. River water contained more depleted hydrogen and oxygen isotopes than precipitation did, implying that the river water mainly came from the upstream catchment. Using a mass balance equation, a comparison of $d$-values of precipitation and groundwater indicated the groundwater consists of $75.5 \%$ wet seasonal sources and $24.5 \%$ dry seasonal sources, representing a distinct seasonal variation of groundwater recharge in the study area.

\section{Acknowledgments}

This study was financially supported by funds from the National Science Council (NSC), Taiwan, under grant NSC 101-2221-E-006-196-MY2 and the Central Geological Survey of Taiwan under grant 102-5226904000-01-02. We would also like to thank Chung-Ho Wang of the Institute of Earth Sciences at the Academia Sinica for help with analyzing the water samples. Special thanks go to the two anonymous reviewers and the editors for their critical reviews and helpful comments.

\section{Author Contributions}

Hsin-Fu Yeh conceived the subject of the article, literature review and contributed to the writing of the paper; Hung-I Lin participated in the composition of the manuscript in the method, results and conclusion sections; Cheng-Haw Lee and Kuo-Chin Hsu provided expertise on groundwater-surface water interactions and hydrogeology in study area; Chi-Shin Wu participated in data processing, elaborated the statistical analysis, and figures.

\section{Conflicts of Interest}

The authors declare no conflict of interest.

\section{References}

1. Gat, J.R. Oxygen and hydrogen isotopes in the hydrologic cycle. Ann. Rev. Earth Planet Sci. 1996, 24, 225-262.

2. Clark, I.D.; Fritz, P. Environmental Isotopes in Hydrology; Lewis Publishers: New York, NY, USA, 1997.

3. Vandenschrick, G.; van Wesemael, B.; Frot, E.; Pulido-Bosch, A.; Molina, L.; Stiévenard, M.; Souchez, R. Using stable isotope analysis $\left(\delta \mathrm{D}\right.$ and $\left.\delta^{18} \mathrm{O}\right)$ to characterise the regional hydrology of the Sierra de Gador, south east Spain. J. Hydrol. 2002, 265, 43-55. 
4. Deshpande, R.D.; Bhattacharya, S.K.; Jani, R.A.; Gupta, S.K. Distribution of oxygen and hydrogen isotopes in shallow groundwaters from Southern India: Influence of a dual monsoon system. J. Hydrol. 2003, 271, 226-239.

5. Gibson, J.J.; Edwards, T.W.D.; Birks, S.J.; St Amour, N.A.; Buhay, W.M.; McEachern, P.; Wolfe, B.B.; Peters, D.L. Progress in isotope tracer hydrology in Canada. Hydrol. Process. 2005, $19,303-327$.

6. Gammons, C.H.; Poulson, S.R.; Pellicori, D.A.; Reed, P.J.; Roesler, A.J.; Petrescu, E.M. The hydrogen and oxygen isotopic composition of precipitation, evaporated mine water, and river water in Montana, USA. J. Hydrol. 2006, 328, 319-330.

7. Blasch, K.W.; Bryson, J.R. Distinguishing sources of ground water recharge by using $\delta^{2} \mathrm{H}$ and $\delta^{18} \mathrm{O}$. Ground Water 2007, 45, 294-308.

8. Li, F.; Pan, G.; Tang, C.; Zhang, Q.; Yu, J. Recharge source and hydrogeochemical evolution of shallow groundwater in a complex alluvial fan system, southwest of North China Plain. Environ. Geol. 2008, 55, 1109-1122.

9. Heilweil, V.M.; Solomon, D.K.; Gingerich, S.B.; Verstraeten, I.M. Oxygen, hydrogen, and helium isotopes for investigating groundwater systems of the Cape Verde Islands, West Africa. Hydrogeol. J. 2009, 17, 1157-1174.

10. Yin, L.; Hou, G.; Su, X.; Wang, D.; Dong, J.; Hao, Y.; Wang, X. Isotopes ( $\delta \mathrm{D}$ and $\left.\delta^{18} \mathrm{O}\right)$ in precipitation, groundwater and surface water in the Ordos Plateau, China: Implications with respect to groundwater recharge and circulation. Hydrogeol. J. 2011, 19, 429-443.

11. Singh, M.; Kumar, S.; Kumar, B.; Singh, S.; Singh, I.B. Investigation on the hydrodynamics of Ganga Alluvial Plain using environmental isotopes: A case study of the Gomati River Basin, northern India. Hydrogeol. J. 2013, 21, 687-700.

12. Dansgaard, W. Stable isotopes in precipitation. Tellus 1964, 16, 436-468.

13. Craig, H. Isotopic variations in meteoric waters. Science 1961, 133, 1702-1703.

14. Gat, J.R. The isotopes of hydrogen and oxygen in precipitation. In Handbook of Environmental Isotope Geochemistry; Fritz, P., Fontes, J.C., Eds.; Springer: Berlin, Germany, 1980; pp. 21-47.

15. Darling, W.G.; Armannsson, H. Stable isotopic aspects of fluid flow in the Krafla, Namafijall and Theistareykir geothermal systems of northeast Iceland. Chem. Geol. 1989, 76, 197-213.

16. Sakai, H.; Matsubaya, O. Stable isotopic studies of Japanese geothermal system. Geothermics 1977, 5, 97-124.

17. Lee, K.S.; Wenner, D.B.; Lee, I. Using H- and O-isotopic data for estimating the relative contributions of rainy and dry season precipitation to groundwater: Example from Cheju Island, Korea. J. Hydrol. 1999, 222, 65-74.

18. Peng, T.R.; Wang, C.H.; Huang, C.C.; Fei, L.Y.; Chen, C.T.A.; Hwong, J.L. Stable isotopic characteristic of Taiwan's precipitation: A case study of western Pacific monsoon region. Earth Planet Sci. Lett. 2010, 289, 357-366.

19. Water Resource Agency (WRA). Investigation of Water Resource in Hualien; Ministry of Economic Affairs: Taipei, Taiwan, 1997; p. 265.

20. Water Resource Agency (WRA). Investigation of Groundwater Resource in Hualien Alluvial Valley; Ministry of Economic Affairs: Taipei, Taiwan, 2005; p. 395. 
21. Water Resource Agency (WRA). Conjunctive Utilization of Surface Water with Groundwater for Hualien Area; Ministry of Economic Affairs: Taipei, Taiwan, 2010; p. 525.

22. International Atomic Energy Agency (IAEA). Guidebook on Nuclear Techniques in Hydrology; IAEA Technical Reports Series No. 91; IAEA: Vienna, Austria, 1983; p. 439.

23. Epstein, S.; Mayeda, T. Variation of ${ }^{18} \mathrm{O}$ content of waters from natural sources. Geochim. Cosmochim. Acta 1953, 4, 213-224.

24. Coleman, M.L.; Shepherd, T.J.; Durham, J.J.; Rouse, J.E.; Moore, G.R. Reduction of water with zinc for hydrogen isotope analysis. Anal. Chem. 1982, 54, 993-995.

25. Wang, C.H.; Peng, T.R. Hydrogen and oxygen isotopic compositions of Taipei precipitation: 1990-1998. West. Pac. Earth Sci. 2001, 1, 429-442.

26. Peng, T.R.; Wang, C.H.; Lai, T.C.; Ho, S.K. Using hydrogen, oxygen, and tritium isotopes to identify hydrological factors contributing to landslides in a mountainous area, central Taiwan. Environ. Geol. 2007, 52, 1617-1629.

27. Yeh, H.F.; Lee, C.H.; Hsu, K.C. Oxygen and hydrogen isotopes for the characteristics of groundwater recharge: A case study from the Chih-Pen Creek basin, Taiwan. Environ. Earth Sci. 2011, 62, 393-402.

28. Yurtesever, Y.; Gat, J.R. Atmospheric waters. In Stable Isotope Hydrology: Deuterium and Oxygen-18 in the Water Cycle; IAEA Technical Report Series No. 210; Gat, J.R., Gonfiantini, R., Eds.; International Atomic Energy Agency: Vienna, Austria, 1981; pp. 103-142.

29. Lu, H.Y.; Peng, T.R.; Liu, T.K.; Wang, C.H.; Huang, C.C. Study of stable isotopes for highly deformed aquifers in the Hsinchu-Miaoli area, Taiwan. Environ. Geol. 2006, 50, 885-898.

(C) 2014 by the authors; licensee MDPI, Basel, Switzerland. This article is an open access article distributed under the terms and conditions of the Creative Commons Attribution license (http://creativecommons.org/licenses/by/4.0/). 